Pedagogía y Saberes n. ${ }^{\circ} 54$

Universidad Pedagógica Nacional

Facultad de Educación. 2021. pp. 125-139

\title{
La tecnología de la información en la cibercultura. Un análisis con la teoría de los códigos*
}

\section{The Information Technology in Cyberculture. An Analysis with the Theory of Codes A tecnologia da informação na cibercultura. Uma análise com a teoria dos códigos}

Miller Antonio Pérez Lasprilla**

Para citar este artículo

Pérez-Lasprilla, M. (2021). La tecnología de la información en la cibercultura. Un análisis con la teoría de los códigos. Pedagogía y Saberes, (54). https//doi.org/10.17227/pys.num54-10527

* Este trabajo hace parte de la tesis doctoral en el énfasis de Educación, Cultura y Desarrollo del Doctorado Interinstitucional en Educación de la Universidad Pedagógica Nacional de Colombia.

** Magíster en Educación, licenciado en Psicología y Pedagogía. Profesor de la Universidad de San Buenaventura, Bogotá, Colombia.

Correo electrónico: paidoperez@hotmail.com

Código Orcid: https://orcid.org/0000-0001-5855-597 


\section{Resumen}

La tecnología de la información es parte de un cambio cultural contemporáneo que configura el concepto de cibercultura. Sin embargo, el uso común del término "cultura", sumado a la falta de consenso académico sobre su definición, dificulta su análisis en relación con aspectos como la producción de hardware y software, la edición genética y las nuevas dinámicas de organización social, económicas y políticas. En este artículo de reflexión se asume una interpretación comunicológica de la cultura a partir de la teoría de los códigos y una revisión del concepto antropológico de la técnica. El resultado de esta reflexión es una interpretación de la tecnología de la información como código y una identificación de posibles puntos de encuentro para entender, desde una perspectiva propiamente culturalista, los fenómenos que constituyen la cibercultura.

\section{Palabras clave}

técnica; tecnología de la información; cibercultura

\section{Abstract}

Information technology is nowadays a part of a cultural change that shapes the concept of cyber-culture. However, the common use of the culture concept, combined with the lack of academic consensus about its definition, makes especially difficult its analysis in terms of hardware production, software programming, genetic edition as well as the new social, economic, and political organization dynamics. As an alternative to this, this text adopts a communicological interpretation towards culture, based on coding theory and a review of the anthropological concept of technique. The result of this reflection is an interpretation of information technology as culture and an identification of possible meeting points which allow understanding the phenomena enclosed in cyberculture, from a cultural -like perspective.

\section{Keywords}

technique; information technology; cyberculture

\section{Resumo}

A tecnologia da informação faz parte de uma mudança cultural contemporânea que configura o conceito de cibercultura. No entanto, o uso comum do termo 'cultura', somado à falta de consenso acadêmico sobre sua definição, torna difícil analisá-lo em relação com aspectos como a produção de hardware e software, edição genética e novas dinâmicas de organização social, econômicas e políticas. Neste artigo de reflexão, assume-se uma interpretação comunicológica da cultura a partir da teoria dos códigos e uma revisão do conceito antropológico de técnica. 0 resultado desta reflexão é uma interpretação da tecnologia da informação como um código e uma identificação de possíveis pontos de encontro para compreender, desde uma perspectiva estritamente culturalista, os fenômenos que constituem a cibercultura.

\section{Palavras-chave}




\section{Introducción}

En la actualidad, los avances de la tecnología de la información permiten entrever la configuración de un nuevo orden cultural que se ha denominado cibercultura o cultura digital, en alusión al control que deriva de la complejización del sistema técnico en el conjunto social. Con este concepto, la mayoría de los análisis de la tecnología de la información se concentran en describir los cambios en las formas dominantes que produce la cultura digital en el ámbito de la investigación y la producción (Levy, 2007) y las nuevas formas de tecnosociabilidad (Ellul, 2003) y biosocialidad (Sloterdijk, 2000), derivadas del uso masivo y especializado del sistema técnico moderno. Según Escobar, "la cibercultura refiere específicamente a nuevas tecnologías en dos áreas: (a) inteligencia artificial, particularmente tecnologías de computación e información; y (b) la biotecnología" (2005, p. 18).

El término cibercultura deriva de una conjunción entre la palabra griega kybērnētes, que significa 'piloto o timonero', y el concepto de cultura. Con el sufijo ciber se alude fundamentalmente a procedimientos orientados por la ciencia moderna para automatizar acciones humanas e intervenir en su programa genético. En cambio, con el concepto de cultura se refiere a un nuevo campo de práctica antropológico: "relacionado particularmente con las construcciones y reconstrucciones culturales en las que las nuevas tecnologías están basadas y a las que a su vez ayudan a tomar forma" (Escobar, 2005, p. 15). No obstante, a pesar de la potencia explicativa del concepto, para entender los cambios sociales que se producen con la técnica moderna tanto el prefijo ciber como el componente cultural del término no han estado exentos de controversias académicas, lo que dificulta su análisis en campos como la organización sociopolítica o educativa. En relación con lo ciber, las discusiones giran en torno al concepto antropológico de la técnica y la forma que tomó en la modernidad con la racionalidad científica. Al respecto, se suelen oponer dos posturas: una, en la que se comprende la tecnología moderna como una forma de democratizar el conocimiento, reducir la desigualdad, aliviar el sufrimiento de las enfermedades e incluso "mejorar" el programa genético del hombre; y otra, en la que se entiende como una forma de manipulación mediática que, al contrario de reducir la desigualdad y democratizar el conocimiento, la profundiza y la agrava en favor de una minoría hegemónica. En este último sentido, también se inscriben las interpretaciones que anuncian una pérdida de la identidad de lo humano con la manipulación genética, con la cual se configuran conceptos como el transhumanismo y el poshumanismo. Por su parte, el componente cultural se ha enfrentado siempre al problema del uso común del término y a la falta de consenso académico en su definición, dado que, en la experiencia cotidiana, con la palabra "cultura" se designan objetos, bailes, muestras gastronómicas, entre otros aspectos que identifican a un grupo social, y en el campo académico, el término se ha identificado con la "alta cultura" europea, modos de vida, prácticas, valores, entre otros aspectos (Narváez, 2013).

Como puede notarse, la discusión no es fácil de sortear, porque casi siempre se inscribe en la dualidad entre apocalípticos e integrados tecnológicos, tal como lo señala Umberto Eco (1965). Mientras unos consideran las ventajas y oportunidades del sistema técnico, otros destacan sus efectos negativos y promueven algún tipo resistencia. Entonces, ¿cómo superar esta constante toma de postura unilateral con el fin de configurar otra comprensión de la cibercultura? ¿Tal vez una más integrada? Hasta ahora, la alternativa más fuerte, naturalmente, ha sido el estudio de la cibercultura desde la perspectiva de la antropología cultural. El problema es que este análisis se suele orientar preponderantemente por una forma de entender lo ciber y por eso la pregunta siempre es por los cambios que produce la tecnología en las formas de vida. Pero, ¿qué decir de la cultura que genera la tecnología de la información? Tal como se mencionó, una de las características fundamentales de la cibercultura es su origen en la racionalidad analítica y categorial moderna, que configuran las ciencias de la computación, la genética y todas las disciplinas que fundamentan los desarrollos tecnológicos contemporáneos. Esta racionalidad se opone, en principio, a la racionalidad del sentido común, signada por las costumbres y la experiencia de la totalidad. De manera que, tal como lo señala Escobar, "cualquier tecnología puede ser estudiada antropológicamente desde varias perspectivas - los rituales que origina, las relaciones sociales que ayuda a crear, las prácticas desarrolladas por distintos usuarios alrededor de estas, los valores que fomenta-" (2005, p. 18). Sin embargo, en el caso de la cibercultura, se asiste a una expresión cultural signada por la lógica de la racionalidad científica que tiene una gramática y unas reglas propias con las cuales explica su funcionamiento y, además, se establece su forma de reproducción y generación.

Por esta razón, en este texto se invierte la pregunta por la cibercultura: primero se destacan las características del componente cultural de lo ciber y luego se ordenan los productos de la técnica que configuran las 
formas modernas de vida. Para este efecto, se asume la perspectiva culturalista desarrollada por Umberto Eco, quien asegura que

la cultura por entero debería estudiarse como un fenómeno de comunicación basado en sistemas de comunicación. Lo que significa que no solo puede estudiarse la cultura de ese modo, sino que, además, solo estudiándola de ese modo puede esclarecer sus mecanismos fundamentales. (1995, p. 44).

También se acude al trabajo Narváez $(2012,2013)$, quien viene proponiendo la recuperación del concepto de cultura como proceso de significación y codificación, más allá del concepto utilizado por el sentido común. Aunque el trabajo de este autor se ha concentrado sobre todo en fenómenos de economía política, considerando el carácter generador de la teoría de los códigos, se entiende aquí que analizar algunos aspectos de la cultura con esta teoría puede iluminar una interpretación más amplia de la tecnología de la información en la cibercultura. De manera que, tal como lo asegura Narváez:

En términos estrictamente comunicativos, la cultura aquí se asumirá como un problema de códigos y, por tanto, su modelo es principalmente lingüístico. De suerte que al hablar de las culturas no se trata principalmente de grupos humanos ni de instituciones u organizaciones, tampoco de objetos, sino de formas de codificación que son, por definición, arbitraria y simbólica. (2013, p. 28).

En ese sentido, el aporte que hace este trabajo a la discusión consiste en un planteamiento propiamente culturalista para el análisis de la cibercultura, con el cual se busca sortear, en parte, los obstáculos interpretativos que derivan de la forma común de entender la cultura. Para ello, primero se acude a la perspectiva antropológica de la técnica con el fin de separar aspectos extralingüísticos y extracomunicativos, tales como la determinación evolutiva de la técnica. Luego, se plantea un modelo que busca entender por separado los objetos y los procedimientos técnicos que derivan en sentidos y usos particulares, y el dominio del código que produce y reproduce la tecnología de la información que les compete a los sujetos. Con el resultado, se revisan las principales discusiones sobre la cibercultura, referidas a la biotecnología, la técnica como esencia y los sistemas técnicos con los cuales se asiste hoy a nuevas formas de producción y reproducción social.

\section{Perspectiva antropológica de la técnica}

Para empezar, en este texto se acude a la característica instrumental y antropológica de la técnica, por tratarse de un mínimo acuerdo entre los teóricos más relevantes del campo. Porque si bien autores como Ellul (2003), Heidegger (2001) y Simondon (2008) difieren en su interpretación del sentido de la técnica moderna, cada uno parte de reconocer su carácter evolutivo y constitutivo en la condición humana. Incluso Heidegger, quien puede considerarse uno de los autores más críticos de la técnica moderna, empieza su disertación en La pregunta por la técnica diciendo: "todo el mundo conoce las dos frases con las que se responde a nuestra pregunta. Una dice: la técnica es un medio para un fin. La otra dice: técnica es un hacer del hombre" (2001, p. 55). Al respecto, autores como Heidegger son enfáticos en señalar que la determinación antropológica de la técnica no es suficiente para entender en qué consiste, por ejemplo, querer dominarla, pero parte de este presupuesto mínimo para adentrarse en sus posteriores análisis.

Pero, ¿en qué consiste la característica instrumental antropológica de la técnica? Básicamente en unas interpretaciones de la evolución de la tecnicidad humana con base en estudios paleontológicos, biológicos y sociales. Desde esta perspectiva, se estudia la técnica en relación con la compensación de desespecialización evolutiva, la configuración del fenómeno que constituye el gesto y la palabra como facultad y las dinámicas de organización social. De manera que reconocer estos mínimos de la discusión puede ordenar el análisis de la tecnología de la información en la cibercultura desde diferentes ángulos teóricos, e incluso puede clarificar aspectos que se dan muy rápido por hecho en la discusión de temas controversiales de la cibercultura.

\section{Concepto antropológico de la técnica: la raíz de lo ciber}

\section{La desespecialización anatómica y la facultad simbolizante del hombre}

La tecnología de la información que constituye la cibercultura tiene raíces muy profundas en la desespecialización anatómica y la facultad de simbolización que caracteriza a los seres humanos como especie: "a lo largo de su evolución, desde los reptiles, el hombre aparece como el heredero de aquellas criaturas que escaparon a la especialización anatómica" (Leroi-Gourhan, 1971, p. 120). En lugar de dientes filosos, pelaje grueso, piernas veloces, visión 
aguda y la rápida autonomía funcional de las crías que caracteriza a la mayoría de los mamíferos, el hombre desarrolló una oposición entre la cara y la mano, pero sobre todo un cerebro especializado que configuró una facultad de simbolización, con lo cual ha intentado compensar su baja dotación orgánica creando elementos y procesos técnicos variados. Por esa razón el gesto que conlleva la desespecialización anatómica y la palabra como expresión de la facultad de simbolización se presenta como un solo fenómeno que configura la técnica y el lenguaje, porque, mientras el gesto ha conformado una serie de movimientos diferenciados y articulados que son posibles por la facultad de nombrar y reconocer el significado de dichos movimientos, la facultad simbolizante, en parte, es el resultado de gestos muy primitivos que provocaron cambios evolutivos en el organismo humano. Según Leroi-Gourhan, "lo que nos es propio y estrictamente propio: la facultad de simbolización, o más generalmente, es esa propiedad del cerebro humano de conservar una distancia entre lo vivido y el organismo que le sirve de soporte" (1971, p. 230). Con ella, cuando por primera vez el hombre sintió hambre, frío o miedo, y además lo hizo consciente, pudo crear medios para cazar, crear abrigos y resguardarse de los depredadores. ${ }^{1}$ En suma, con la configuración evolutiva de la técnica como un modo de hacer del hombre y un medio para un fin, el ser humano pudo expresar su pensamiento con formas que a la postre han configurado sistemas de registro, conservación y transmisión de información, como la tecnología de la información moderna.

1 Para el propósito de este texto, con el concepto de facultad de simbolización se configuran, por lo menos, dos perspectivas de análisis: una como capacidad creativa y otra como cualidad de la facultad. Según Virno (2005), la facultad de simbolización, de la que habla Leroi-Gourhan (1971), se puede catalogar como una facultad creativa que siempre excede cualquier tipo de determinación significante, dado que "todo hablante hace 'un uso infinito de medios finitos': sus enunciados, no derivando de estímulos externos ni de estados interiores, están inclinados a la innovación y hasta la imprevisibilidad" (p. 185). Por lo mismo, esta facultad representa una posibilidad exponencial de significación de la experiencia de sí, los otros y lo otro, pero a la vez, es fuente de un resto de sentido que excede cualquier idea estable del mundo. En cuanto a la cualidad de la facultad, se reconoce en la obra de (2001) la interpretación de la técnica como esencia (la técnica), en oposición a su expresión (lo técnico). Para Heidegger: "la técnica no es igual que la esencia de la técnica. Si nosotros buscásemos la esencia del árbol, tendríamos que elegir aquello que domina a todo árbol en cuanto árbol, sin ser ello mismo un árbol, que se pueda encontrar entre los restantes árboles" (2001, p. 55). La facultad creativa se abordará desde la teoría de los códigos, y la facultad como esencia se presentará en la parte final, del lado de la técnica, en la obra de Heidegger.
Para Leroi-Gourhan (1971), los primeros símbolos del lenguaje datan del año 30000 a. C., cuando aparecieron las primeras formas figurativas en las que apenas pueden reconocerse rasgos distintivos de animales. Pero luego, a través de un lento proceso de agrupamiento urbano y desarrollo de la metalurgia, se consolidaron los sistemas de escritura, que volvió más eficiente el registro, la conservación y la transmisión de la información. Así, según el etnólogo francés:

se puede situar hacia 3500 antes de nuestra era (2500 años después de la aparición de las primeras aldeas) los primeros gérmenes mesopotámicos de la escritura. Dos mil años más tarde, hacia 1500 antes de nuestra era, los primeros alfabetos con vocales se instalaron en Grecia. En 350, la filosofía griega está en pleno auge. (p. 207)

No obstante, el cambio de técnica a tecnología de la información realmente se empezó a gestar en el siglo XVIII, con base en la racionalidad científica moderna que redefinió la técnica como: "el uso del conocimiento científico para especificar modos de hacer cosas de manera reproducible" (Castell, 2000, p. 56). ${ }^{2}$ Desde esta perspectiva, la tecnicidad evolutiva del hombre empezó a ser interpelada por un acumulado de información que se organiza e interpreta de forma analítica y categorial, de acuerdo con un método de validación de los valores de verdad de los enunciados. Precisamente, con base en esta forma de pensar se perfeccionó la imprenta, y con ello se inició un cambio sustantivo en el proceso de registro, almacenamiento y difusión de la información, lo que ha venido acelerando los procesos de enculturación humana, lo cual, a la vez, produjo otros desarrollos técnicos. Entonces, después de la imprenta (con el telégrafo, la radio y el teléfono, hasta llegar a la electrónica) se inició un proceso exponencial de desarrollo tecnológico que llevó a la creación del microchip; hoy se presenta como un sistema de súpercomputadoras interconectadas y se proyecta como un sistema de automatización, potenciación y transformación de las cualidades que han definido históricamente la condición humana.
2 Heidegger (2001) cuestiona esta interpretación sobre el significado de la tecnología, pero entendemos que se refiere a una dimensión que no es objeto de discusión en este texto. En la pregunta por la técnica, Heidegger afirma: "como la esencia de la técnica moderna descansa en la estructura de emplazamiento, por esto aquélla tiene que emplear la ciencia natural exacta. De ahí surge la apariencia engañosa de que la técnica moderna es ciencia natural aplicada" (2001, p. 24). Sin embargo, en la parte final del texto se presenta una referencia tangencial de esta interpretación. 
Criterio de organización sociopolítica: la tecnicidad humana como transformación de la especie en grupo étnico

La tecnología de la información también tiene como antecedente, además de la ocupación de un territorio y la permanencia allí, la contigüidad con otros territorios que permitían un acceso permanente a los alimentos y los medios materiales de subsistencia, porque la cantidad y variedad de ellos determinan la densidad del grupo poblacional, así como el eventual desarrollo técnico, económico y social: "para los últimos cuarenta mil años, puede considerarse esta situación como cierta. El paso de la especie zoológica a la 'especie étnica' implica inevitablemente un tal agrupamiento de los hombres" (Leroi-Gourhan, 1971, p. 156).

Los avances en el almacenamiento agrícola y la cría de animales por la ocupación de un territorio, y el intercambio pacífico y bélico de productos técnicos y personas generaron la posibilidad de cubrir el consumo alimentario de individuos que se dedicaban a prácticas diferentes a la producción de alimentos, tales como la cestería, la cerámica y el tratamiento de metales. De esta forma, se configuró la figura del artesano, en oposición a la del sacerdote, cazador, guerrero, agricultor, entre otros, que se gestaron en un sistema social que buscaba mantenerse en el territorio de manera sedentaria.

A partir de este momento, el organismo colectivo se hace preponderante, de manera cada vez más imperativa, y el hombre se transforma en el instrumento de una ascensión tecno económica, a la cual presta sus ideas y sus brazos. Así, la sociedad humana se convierte en la principal consumidora de hombres, bajo todas las formas, por la violencia o el trabajo. (Leroi-Gourhan, 1971, p. 183)

En la actualidad, tal organización sigue vigente en los aspectos fundamentales. Por supuesto que se han acumulado innovaciones técnicas que plantean el producir más allá de la manualidad; pero es justo decir que la organización jerárquica de las sociedades humanas y el intercambio pacífico y bélico de las innovaciones técnicas que se encuentran en la base de la "civilización" continúan estructurando relaciones de poder que derivan en expresiones técnicas de conservación, explotación y defensa. Por esa razón, además de la consideración de la facultad de simbolización, con todo y el resto de sentido que produce, es necesario analizar fenómenos como la tecnología de la información a la luz de la configuración política y económica de las sociedades humanas.

\section{La tecnología de la información como cultura}

En el tomo I de La era de la información, Castell ofrece la siguiente definición de la tecnología de la información, la cual se alinea perfectamente con el concepto de cibercultura que se está discutiendo en este texto:

Entre las tecnologías de la información incluyo, como todo el mundo, el conjunto convergente de tecnologías de la microelectrónica, la informática (máquinas y software), las telecomunicaciones/ televisión/radio y la optoelectrónica. Además, a diferencia de algunos analistas, también incluyo en el ámbito de las tecnologías de la información la ingeniería genética, su conjunto de desarrollos y aplicaciones en expansión. (2000, p. 56)

En esta descripción, Castell identifica, por un lado, las máquinas como instrumentos de uso y, por el otro, el software como programas algorítmicos y estructura de datos que permiten el registro, la transmisión y el acceso a la información digitalizada con base en un sistema de intercambio de señales. Asimismo, reconoce el código genético como un sistema de información manipulable, por constituir un código que permite "leer" y "escribir" la organicidad humana, de manera que sobre esta base resulta posible presentar aquí la tecnología de la información como cultura.

\section{Producción de elementos \\ de uso, programación de software y edición genética}

De acuerdo con Eco (1995), la producción de elementos de uso, como una computadora, un celular, un cable de fibra óptica, entre otros, se puede entender como cultura siempre y cuando cumpla con tres características: 1) un ser pensante establece una función para un objeto natural o creado; 2) el ser pensante ha denominado al objeto como un objeto que sirve para algo, y 3) el ser pensante está en condiciones de reconocer el mismo objeto o un objeto similar en otro momento. Es decir, primero, con la facultad de simbolización, un ser humano pone ahí delante lo que se encuentra oculto, con su tecnicidad le da una forma y establece para ello una función; luego establece o reproduce para el objeto una convención (regla) entre un contenido posible y su expresión para denominar su utilidad, y, por último, es capaz de reconocer ese mismo objeto con base en la convención que instituyó o reprodujo para denominarlo. De esta forma, el hardware, el software y la edición genética se pueden entender como la expresión de un proceso de "desocultamiento", signado por la tradición del pensamiento moderno, que tiene como base la tecnicidad y la facultad simbolizante de los seres humanos. 
Empero, es preciso aclarar que la semiótica no tiene nada que decir acerca del continuum material que subsiste en la expresión del hardware (los metales y el plástico), ni del continuum amorfo de hechos y conceptos de donde el hombre selecciona sustancias de contenido: el primer fenómeno es objeto de la física y la química, y el segundo, de la fenomenología como estudio de la consciencia y las estructuras de la experiencia. Por esa razón, en relación con este aspecto, solo se tratará el proceso que permite nombrar, producir y reconocer los aparatos electrónicos y las aplicaciones de software, es decir, se abordará el aspecto propiamente cultural de la tecnología de la información.

\section{La forma de contenido y de expresión de los dispositivos electrónicos y las aplicaciones de software}

En consideración a la teoría de los códigos, la significación de un objeto o sistema técnico electrónico se puede explicar a partir del esquema de la función semió- tica, propuesto por Eco (1995), con base en Hjelmslev (1984), en el cual establece una correlación entre la forma expresión y la forma del contenido de un código:

Hay sistema de significación (y, por tanto, código), cuando existe una posibilidad establecida por una convención social de generar funciones semióticas, independientemente de que los funtivos de dichas funciones sean unidades discretas llamadas "signos" o grandes porciones del habla, con tal de que la correlación haya sido establecida precedentemente y preliminarmente por una convención social. (Eco, 1995, pp. 18-19)

De acuerdo con este esquema, tanto la expresión como el contenido de la significación de los dispositivos electrónicos se pueden esquematizar como se muestra en la tabla 1.

Tabla 1. Expresión y contenido de los dispositivos electrónicos y las aplicaciones de software

\begin{tabular}{|c|c|c|c|}
\hline \multicolumn{2}{|c|}{ Expresión } & \multicolumn{2}{|c|}{ Contenido } \\
\hline \multicolumn{2}{|c|}{ Código sintáctico } & \multicolumn{2}{|c|}{ Código semántico } \\
\hline Sustancia o materialidad & Forma de la expresión & Forma del contenido & $\begin{array}{l}\text { Sustancia del } \\
\text { contenido }\end{array}$ \\
\hline $\begin{array}{l}\text { Soporte material de la } \\
\text { expresión: plástico y } \\
\text { metales, luz, energía, etc. }\end{array}$ & $\begin{array}{c}\text { Forma que toma } \\
\text { la expresión de los } \\
\text { dispositivos electrónicos: } \\
\text { pantallas electrónicas, } \\
\text { teclados, cables de fibra } \\
\text { óptica, entre otros. } \\
\text { Forma que toman } \\
\text { las aplicaciones de } \\
\text { software: arquitectura de } \\
\text { información, imágenes, } \\
\text { palabras, audios, etc. }\end{array}$ & $\begin{array}{c}\text { Forma en que se organizan } \\
\text { los significados: } \\
\text { - figurativa/narrativa } \\
\text { - abstracta/argumentativa }\end{array}$ & $\begin{array}{l}\text { Lo que representa y dice el } \\
\text { sujeto a partir de las formas } \\
\text { de expresión y contenido. } \\
\text { Es la apropiación y } \\
\text { creación de significados } \\
\text { que solo puede hacer } \\
\text { el sujeto si conoce o } \\
\text { instituye las formas. }\end{array}$ \\
\hline
\end{tabular}

Fuente: elaboración propia con base en Narváez (2013, p. 48).

Así, la sustancia expresiva constituye el continuum material de donde el hombre selecciona lo que le permite crear los objetos; por ejemplo, el silicio, el estaño, el cobre, el litio, entre otros metales, que extrae y separa de la tierra a partir de procesos químicos o transformaciones de la energía. Por su parte, la forma de la expresión corresponde a la "apariencia" que adquieren los objetos por el tratamiento técnico o trabajo físico que hace un ser humano con la sustancia expresiva; por ejemplo, la forma rectangular de las pantallas electrónicas o de las computadoras, o la visualización de las aplicaciones de software: iconos, imágenes, palabras, audios.

En tanto, la forma del contenido señala la manera en que los seres humanos organizan los significados de la forma de la expresión; por ejemplo, de manera figurativa (tratando de representar fielmente la realidad observada), narrativa (contando una historia), 
de forma abstracta ( $\sin$ correspondencia literal) o argumentativa (dando razones lógicas, medibles y verificables de lo dicho). La sustancia del contenido alude a los aspectos conceptuales del significado que ocurren en la mente de los seres humanos a partir de las formas de expresión y de contenido; esta dimensión señala el tipo de apropiación y creación de significados que solo puede hacer el sujeto si conoce las formas. De esta manera, entre la sustancia expresiva y de contenido del hardware y el software se hallan las reglas que relacionan elementos de las formas de expresión con elementos de las formas de contenido, es decir, los códigos.

\section{Los sistemas código para nombrar, producir y reconocer los aparatos \\ electrónicos y las aplicaciones de software}

Comúnmente, se producen confusiones a la hora de comprender la tecnología de la información en la cibercultura, porque, tal como lo advertía Eco (1995), en la experiencia común se denomina "código" a varios fenómenos subyacentes del proceso de comunicación que conducen a tomar la parte por el todo. Por eso, para evitar dicha confusión propone clasificar los fenómenos que por lo general reciben el nombre de código para poder establecer sus diferencias. Con ello, sugiere llamar sistemas código (s-código) a los casos que corresponden a estructuras y esquemas independientes de procesos de significación y comunicación, y código, propiamente dicho, a la regla que permite relacionar elementos de un sistema código con los elementos de otros sistemas código. En orden de exposición, se refiere a los sistemas código sintáctico, semántico y pragmático.

Sistema código sintáctico: corresponde a una serie de unidades discretas no significativas reguladas por leyes combinatorias que permiten configurar mensajes a través de posiciones, oposiciones y ausencias de unidades. Como ejemplo se pueden citar los códigos binario y alfabético:

\section{1}

\section{Casa / pasa}

La regla del sistema sintáctico binario permite cambiar o eliminar las posiciones de alguno o varios números para transmitir una señal diferente. Por ejemplo, en una línea de código binario, el número 0 y el número 1 se organizan e intercambian, de tal manera que un sistema transmisor emite una señal y con ello se obtiene una respuesta esperada en el sistema receptor. Lo mismo ocurre con el código alfabético, pero con sutiles diferencias, porque en lugar de números se compone de letras y, además, dispone de una regla combinatoria de posiciones y oposiciones con base 27 unidades discretas. Por esa razón, puede decirse que tanto el código binario como el alfabético son digitales, independientemente de si el soporte es una hoja de papel o una pantalla electrónica porque, en últimas, los dos corresponden a un sistema código sintáctico que permite configurar mensajes con unidades discretas (dígitos o letras) no significativas.

En relación con el código sintáctico, la confusión más común en el análisis del uso de las tecnologías de la información en la cibercultura es considerar que un sistema, como el binario o el alfabético, tiene la propiedad de producir significados con la simple emisión y recepción de señales de un sistema técnico. Y es que por causa de la novedad de los dispositivos electrónicos, los programas de software y la velocidad de la transmisión, se suele olvidar la siguiente diferencia básica entre la "comunicación" entre dispositivos electrónicos y la comunicación que involucra a los seres humanos: entre una computadora (emisor) y otra (receptora) puede darse un paso de señales a través de un canal (un cable de fibra óptica o el espectro radioeléctrico), y en este caso, la "comunicación" se considerará efectiva si se produce un alto grado de equiprobabilidad entre la información enviada y la información recibida, pero en los seres humanos esta equiprobabilidad se observa en la respuesta interpretativa de un receptor con base en un código semántico. De esta forma

el término /información/ tiene dos sentidos fundamentales: (a) significa una propiedad estadística de la fuente, es decir, designa la cantidad de información que puede transmitirse; (b) significa una cantidad precisa de información seleccionada que se ha transmitido y recibido efectivamente. (Eco, 1995, p. 71)

De ahí que sea necesario diferenciar el paso de información de una máquina a otra, la información que le envía un ser humano a otro por medio de sistema electrónico y la respuesta interpretativa que produce la información en un receptor humano, porque, en efecto, el primer caso corresponde a un sistema sintáctico, pero la segunda y tercera posibilidad comprometen la capacidad que tiene un ser pensante para expresar el producto de pensamiento con base en unas reglas convencionales, es decir, a través de un código semántico y un código pragmático o de "comportamiento".

En la producción de elementos de uso, el código sintáctico funciona como un sistema de conservación de la información que describe y especifica las cadenas de actos que se requieren para lograr el efecto 
deseado. Con la información codificada de esta forma, un ser pensante puede registrar el procedimiento que siguió para producir determinado objeto o sistema, de manera que él mismo, u otra persona que conozca la regla usada para registrar la información, puede recuperarla para repetir o mejorar el resultado con base en ejercicios habituales. En el caso de la programación de software, el código sintáctico funciona como un sistema lógico de procesamiento de información basado en algoritmos y estructuras de datos. Sin embargo, en el caso de la edición genética, el código sintáctico lo hace como un conjunto de reglas que define cómo se transcribe una secuencia de nucleótidos en el ARN a una secuencia de aminoácidos en una proteína. De acuerdo con Lacadena: "por edición genómica se entiende un tipo de ingeniería genética en la que el ADN es insertado, eliminado o reemplazado en el genoma de un organismo utilizando enzimas del tipo nucleasas (denominadas “tijeras moleculares)" (2017, p. 3).

Sistema código semántico: corresponde, según la explicación más básica, a una serie de nociones que pueden convertirse en una serie de contenidos de una posible comunicación con base en una estructura de posición y oposición (o diferencias) de nociones que depende de los seres humanos; por ejemplo, se entiende lo que significa perro en oposición a un gato, en un campo semántico de animales domésticos. El sistema semántico constituye toda la nebulosa de posiciones, oposiciones, ausencias y ejes de las nociones posibles que un ser humano puede establecer según su facultad simbolizante para darle significado a su experiencia.

Por eso, para realizar un análisis componencial de unidades culturales, como el hardware, el software o el código genético, es necesario recortar esa nebulosa con el concepto de campo semántico, entendido como una clasificación de elementos comunes, pero a la vez diferentes entre sí. Por ejemplo, en el campo semántico de los peces, una ballena es un pez y comparte esa característica con un tiburón, y a la vez se diferencian porque la ballena es un pez de gran tamaño, y el tiburón es más pequeño y con dientes afilados.

De esta forma, unidades culturales como las computadoras, los celulares, el teclado, el sistema operativo, la conexión wifi, entre otras, constituyen en este texto el campo semántico de las tecnologías de la información. Sin embargo, como el significado no es simplemente una posición en un campo semántico determinado, sino también "(I) una red de posiciones dentro del mismo campo semántico y (II) una red de posiciones dentro de campos semánticos diferentes" (Eco, 1995, p. 137), para el análisis componencial sería necesario considerar el lugar de las tecnologías de la información en otros campos semánticos. En todo caso, lo más importante de esta conceptualización es reconocer que la significación de la tecnología de la información depende de un ser pensante capaz de nombrar y reconocer la función de un objeto y no de la simple reproducción de la información en equipos electrónicos.

Desde esta perspectiva, el hardware, el software y la edición genética, que constituyen la tecnología de la información, se pueden entender, por lo menos, de tres formas:

- Un elemento de uso, como una computadora o un programa informático, constituye un signo en una cadena de signos en un campo semántico: una computadora o programa informático se representa a sí mismo como tal en una comunicación.

- El hardware, el software y la edición genética son la materialización técnica que realiza un ser humano a partir de uno o varios campos semánticos: los conocimientos en física, química y matemáticas permiten a un ser humano crear o reproducir aparatos electrónicos, programar aplicaciones de software y editar el código genético.

- Una computadora o un cable de fibra óptica sirven como sustancia expresiva de señales y códigos sintácticos que pueden ser parte de una comunicación: los dispositivos electrónicos funcionan como soporte material para emitir y recibir información codificada.

Ahora bien, esto no significa que toda interpretación sobre la tecnología de la información corresponda en rigor a su campo semántico, porque una cosa es el sentido denotado por el emisor (el sentido que corresponde directamente al campo semántico que produce la información) y otra, los sentidos connotados por el destinatario (los sentidos posibles que puede construir una persona articulando otros campos semánticos de su sistema de significación). Por ejemplo, un biólogo al referirse a un perro puede denotar 'mamífero carnívoro de la familia de los cánidos', pero otra persona que no ha construido el campo semántico de la biología puede connotar un significado como 'amigo fiel e incondicional'. Por supuesto, el biólogo también puede connotar el segundo significado, pero sin el campo semántico de la biología, la segunda persona difícilmente podrá connotar el sentido denotado por el biólogo. En consecuencia, las posibilidades que tiene disponible un ser pensante para ofrecer una respuesta interpretativa superan cualquier sentido unívoco de la denotación, y constituyen un código pragmático o de comportamiento. 
Sistema código pragmático: consiste en una serie de posibles respuestas de comportamiento por parte del destinatario que son independientes del sistema semántico y que pueden ser motivadas por un sistema sintáctico cualquiera. En el modelo informacional, cuando una máquina transmite una información a otra, la señal estimula una respuesta, pero cuando es un ser humano el que responde, ocurre una significación y no simplemente la respuesta a un estímulo, porque este puede significar un mensaje basado en una significación precedente. Así, una expresión denota un significado, pero puede connotar otros cuando un ser humano lo recibe; de esta manera, cuando es un ser humano el receptor de la información, caben posibilidades de interpretación y respuesta que exceden el sentido unívoco que pueda tener la denotación.

La mayoría de los estudios de recepción que identifican la forma en que los usuarios interpretan e incorporan la tecnología de la información en sus formas de vida se fijan en el sentido connotado. De esta perspectiva, surgen los conceptos de "cultura digital" y "cibercultura" de los que habla Pierre Lévy (2007), así como los análisis desde algunas perspectivas humanistas que se fijan en la "destrucción" de tradicionales formas de vida por causa de la técnica moderna. Sin embargo, desde estos enfoques se suelen perder de vista las reglas convencionales que se encuentran detrás de las respuestas del destinatario, y con ello, las claves que permiten explicar la estructura generadora de estas expresiones de la cultura. Por eso, como ya se dijo, Eco (1995) propone llamar "código" a la regla que asocia algunos elementos del sistema sintáctico con elementos del sistema semántico o pragmático para establecer que ciertas expresiones corresponden a determinado significado y respuestas específicas. Según el autor, solo este tipo de reglas pueden denominarse con propiedad "código", porque los demás casos serían en realidad sistemas inferiores de codificación.

Así, con el código propiamente dicho estamos en condiciones de definir los siguientes cinco aspectos de la tecnología de la información como cultura:

- Campos semánticos: con los cuales se pueden crear objetos y sistemas técnicos modernos, como la física, la química, la matemática, entre otros.

- Procedimientos técnicos: descripción de las cadenas de actos necesarias para la concretización técnica. ${ }^{3}$

3 Siguiendo a Sloterdijk (2012), el dominio de los procedimientos técnicos depende de la ejercitación constante.
- Reproducción técnica: forma de producir de modo repetitivo a partir de una cadena de actos codificada.

- Concretización técnica: forma y contenido que adquieren los objetos por la acción del hombre

- Invención técnica moderna: nueva relación entre la expresión y el contenido con base en un dominio del código de la tecnología de la información, es decir, con la construcción de campos semánticos de disciplinas formales como la física, la matemática, la química y el conocimiento de las reglas de interpretación y construcción de los enunciados que identifican a la ciencia moderna.

\section{El código de la tecnología de la información}

Con lo dicho hasta ahora puede concluirse que, como la tecnología de la información es la expresión técnica orientada por principios de la tradición científica moderna, su código corresponde a elementos del sistema código sintáctico y elementos del sistema código semántico que constituyen las reglas para componer e interpretar esta forma de la cultura. Según Mockus et ál., esta "se caracteriza por un modo de conocer que se codifica por escrito, se basa en la discusión racional científica, el cálculo, el diseño y la acción orientada y organizada racionalmente" (1994, p. 63). Huelga decir que la creación o reproducción de los dispositivos que configuran el hardware, el software y la edición genética requiere el dominio de las reglas de codificación de la racionalidad moderna, pero también el dominio de los campos semánticos que constituyen la física, la matemática, la química, entre otras disciplinas científicas.

Para Narváez (2013), el código de esta forma de la cultura, que él denomina alfabética por su estrecha relación con este código sintáctico, se caracteriza por formas de expresión alfabética, argumentativa y formas de contenido abstracta, propias de la tradición ilustrada, en oposición de la cultura común, cuyas formas de expresión y contenido corresponden a la tradición oral-icónica y narrativa asociada al mito. De manera que el dominio del código de la cultura alfabética y, específicamente, de la relacionada con los campos semánticos de producción de la tecnología de la información constituyen la condición para interpretar y reproducir técnicamente esta forma de la cultura.

Retomando a Eco (1995), en relación con el dominio del código, se pueden generar dos posibilidades en los extremos: en el primero, se produce un nivel creador que implica una hipercodificación, entendida 
como la propuesta de una regla adicional, y el segundo consiste en una hipocodificación como apropiación parcial del código; es decir, un aprendizaje a medias de las reglas y los campos semánticos que constituyen las disciplinas formales. En el caso de la hipercodificación, un ser pensante domina la correspondencia-sintáctica semántica del código de la tecnología de la información y así puede reproducir, interpretar y derivar nuevas expresiones de la técnica que complejizan el código. Por el contrario, en el caso de la hipocodificación se produce una falta de correspondencia sintáctico-semántica que obstaculiza la reproducción de la expresión técnica, lo cual, además, limita la posibilidad de crear nuevas expresiones técnicas.

En síntesis, en consideración de la teoría de los códigos, tener algún dominio de la tecnología de la información significa estar en posesión de sus campos semánticos, pero sobre todo de las reglas que configuran el código con el cual se produce la información, porque con las reglas un ser pensante es capaz de hacer una decodificación de la información, puede producir información del mismo campo semántico de la fuente y es capaz de usar algo (o proceder) conforme a los contenidos que entraña la información.

\section{Una lectura antropológica y culturalista de la tecnología de la información en la cibercultura}

Con la explicación de los aspectos estructurales de la teoría de los códigos, ahora es posible intentar una lectura propiamente culturalista de algunos aspectos de la perspectiva antropológica para el análisis de la tecnología de la información en la cibercultura.

\section{La desespecialización anatómica y la edición genética}

Con la tecnología de la información, la compensación de la desespecialización evolutiva ha ido más allá de la simple superación técnica de las necesidades básicas de alimentación y seguridad, para inscribirse en la transformación o "mejoramiento" de la especie por medio de la ingeniería genética. Con la secuenciación del genoma humano, que completaron científicos del National Human Genome Research Institute en el 2006, se aceleró un proceso de edición genética que ha derivado en discusiones de orden ético, como las propuestas por Habermas (2010) sobre las implicaciones que surgen de la eugenesia positiva y negativa en la comprensión de lo humano.
Esta perspectiva del cuerpo humano como código también ha suscitado polémicas de aparente tinte político, como las analizadas por Donna Haraway (1995), en las que se afirma una continuidad entre naturaleza y cultura con base en la figura del cíborg: organismo biológico aumentado tecnológicamente. En esta línea se inscriben además posturas posorgánicas, con las cuales se esbozan discusiones sobre la definición de lo humano que configuran conceptos como poshumanismo y transhumanismo (Kurzweil y Grossman, 2004).

En relación con este aspecto, la teoría de los códigos puede aportar aspectos conceptuales del código semántico, en el cual se establece una estrecha relación entre el sistema perceptivo y la construcción de significados que actualizan y complejizan los campos semánticos con los que se produce y reproduce la tecnología de la información. Desde este ángulo, la máquina de soñar, de amar y pensar, que avizoran algunas lecturas posorgánicas, parece fijarse en los significados y sentidos constituidos por un ser pensante; no obstante, estas lecturas posorgánicas parecen ignorar el lugar del cuerpo en la manifestación del gesto y la palabra que configura su tecnicidad, porque si bien un sistema de registro, almacenamiento, procesamiento y gestión de la información puede lograr un gran nivel de complejidad, con ello no resulta posible reproducir técnicamente el proceso de selección rasgos del estímulo perceptivo que configura el proceso de significación. Este aspecto se observa sobre todo en la configuración de los llamados "mundos virtuales", en los que se estimulan los sentidos de la visión y la audición, pero no los sentidos químicos del gusto y el olfato. Según Eco (1995), para construir los significados, los seres humanos seleccionan solo algunos rasgos de la percepción densa del continuum material, con los cuales producen los artificios expresivos y la representación semántica de acuerdo con leyes de semejanza; esta posibilidad se encuentra atada a la configuración evolutiva del gesto y la palabra.

Retomando lo dicho por Leroi-Gourhan (1971), entre naturaleza y cultura no habría ruptura, sino continuidad y, por tanto, no sería posible separar el proceso de producción de significados del organismo que configura el gesto. Sin embargo, más allá del modelo perceptivo, sobre el cual no hay un acuerdo para determinar si este condiciona el significado o si, por el contrario, este aparece condicionado primero por las convenciones culturales (Narváez, 2013), se halla la dificultad de reproducir la capacidad de habitar el porvenir con base en la facultad de simbolización. Bien lo dice Rodríguez cuando afirma: 
si hay algo íntimo en el hombre, pero también en cualquier ser vivo, es esa relación entre lo actual y lo virtual que ninguna máquina podrá recrear. La máquina solo existe en lo actual y no puede habitar "la recurrencia de porvenir en el presente". (2007, p. 13)

\section{La facultad creativa del lenguaje}

En la gramática universal de Chomsky, que reivindica un invariante biológico, la facultad de lenguaje se entiende como una cualidad innata y creativa de orden genético que deriva de la evolución del hombre (metahistoria), mientras que, desde otras perspectivas, como la arqueológica-genealógica foucaultiana, se asume en gran parte como una capacidad adquirida y determinada históricamente por la producción y el poder.

La discusión sobre la relación entre lo innato y lo adquirido del lenguaje ha sido fuente permanente de debates, que han derivado en interpretaciones que reconocen una relación permanente entre lo innato y lo adquirido, pero con algunos matices. Para mostrarlo, Paolo Virno (2005) reseñó el debate televisivo entre Chomsky y Foucault en Eindhoven (Holanda), en el año 1971, a propósito de la naturaleza humana y su relación con el lenguaje. Según Virno (2005), la perspectiva chomskiana ataca el relativismo histórico de Foucault, acusándolo de disolver la naturaleza humana en el carácter circunstancial de su experiencia, mientras la mirada particular de Foucault cuestiona la explicación naturalista de lo humano, siempre igual a sí misma, en contra de la experiencia histórica. Esta misma distinción puede reconocerse en lo concerniente al desarrollo del lenguaje en las teorías del desarrollo intelectual propuestas por Piaget y Vigotsky. Mientras el primero traza una línea de la inteligencia al lenguaje, el segundo pone el acento en la experiencia, es decir, en el carácter sociohistórico del desarrollo en relación con los procesos de maduración. Asimismo, la discusión ha transcurrido en el margen de la distinción entre lengua y habla propuesta por Saussure (1982) para situar en algunos casos la lengua como el fenómeno adquirido del lenguaje, en oposición al habla como capacidad de producir el lenguaje articulado y la exteriorización del pensamiento a través de símbolos.

La gramática generativa supone la existencia de reglas y esquemas que constituyen un invariante común de todas las lenguas, y la perspectiva foucaultiana señala que esas reglas se instituyen histórica y socialmente de manera contingente, sin responder a un principio tal de "naturaleza humana". Al respecto, Paolo Virno señala: el invariante biológico nunca puede ser separado del cambiante decurso histórico: pero este no es argumento suficiente para negar ese invariante como tal, o para desatender los modos en los que permaneciendo invariante, claro irrumpe sobre la superficie de los diversos sistemas sociales y productivos. (2005, pp. 188-189)

Con lo anterior, Virno sugiere una interrelación dinámica entre estos planos. Para mediar en la discusión, apela al concepto de individuación y transindividuación propuesto por Gilbert Simondon (2008). De esta forma afirma que Chomsky se centra en la individuación que configura una metahistoria, ignorando lo transindividual como aquello que escapa a los individuos y se instala entre ellos. Lo transindividual corresponde a lo que une a los individuos, pero que no le pertenece a ninguno; es el vínculo entre la especie y el individuo. Este carácter transindividual constituye un espacio potencial indeterminado que configura el espacio público potencial, que es ignorado por la perspectiva cognitivista centrada en la interacción individual (mentes conscientes). Así, no desconoce que el lenguaje se produzca por factores innatos y adquiridos, pero agrega algunos matices que evitan una interpretación totalitaria de cualquier lado. Entonces, para discutir los fenómenos de la cibercultura, es necesario superar las dos posturas extremas que presentan estos autores en lo concerniente a la "disolución de la metahistoria en la historia empírica (Foucault) o reabsorción de la historia en la metahistoria" (Virno, 2005, p. 192).

\section{Perspectiva ontológica de la tecnología de la información}

Por su parte, la perspectiva que podemos llamar ontológica, por referirse a la pregunta por la esencia de la técnica, recae en la figura de Heidegger (2001) como el filósofo que primero, y de manera más notoria, llamó la atención sobre los cambios que genera la técnica moderna en las formas de vida de los seres humanos. Desde su perspectiva, la pregunta ontológica por la técnica conduce a su esencia, es decir, a lo que es, y no a sus productos, tales como una herramienta o un procedimiento. Por esa razón, en el célebre ensayo sobre la pregunta por la técnica (2001), el filósofo alemán empieza por definir la esencia de la técnica como un modo de desocultar, en oposición a los objetos que adeudan esta forma de hacer presente lo que se encuentra oculto, que en últimas conduce a la verdad. Luego, con ello introduce una crítica a la técnica moderna, acusándola de constituir una forma de solicitar existencias que no corresponden a la esencia de la técnica. De acuerdo con Heidegger, cuando el hombre responde a la estructura de tal 
emplazamiento de la técnica moderna corre el riesgo de extraviarse en la determinación de aquello que sabe que va a encontrar, y de esa forma, no solo se aleja de la verdad, sino que corre el riesgo de no encontrarse consigo mismo.

En consecuencia, y haciendo una transposición atrevida de la tesis de Heidegger (2001) — hasta donde sea posible-, puede decirse que la esencia de la tecnología de la información (como técnica moderna) no es el dispositivo electrónico, las redes de conectividad o el software que sirve para registrar, almacenar y compartir la información, ni tampoco es la información o el conocimiento codificado que da origen o que reproduce esta forma de expresión técnica, sino que constituye aquello que se revela a nuestro estar como un emplazamiento que exige una realización. A partir de esto, la estructura de emplazamiento de la técnica moderna pone en vilo la libertad del hombre, porque esta le solicita lo que sabe que va a encontrar. Por eso, como alternativa, sugiere volver a formas de vida que conlleven una relación directa con el entorno "natural", con el fin de experimentar, según él, la esencia de la técnica como forma primigenia de acceder a la verdad. Esto significa, en principio, una distancia con la racionalidad moderna y, en últimas, una resistencia a incorporar la tecnología de la información como forma de vida, por representar una especie de enajenación del pensamiento. Para Heidegger, ciertas formas de expresión cultural, como la forma de vida de los antiguos griegos o la apacible vida en el campo, lejos de la influencia de la racionalidad moderna, haría posible encontrarse consigo mismo a través de un hacer salir de lo oculto porque, en lugar de interpretar, estas formas de vida conducen a percibir, es decir, a dejar venir lo que se encuentra oculto al claro del ser. Esta forma de entender la técnica comparte otras posturas que intentan recomponer las relaciones premodernas de la técnica como una experiencia de la totalidad, lejos del utilitarismo y el sentido productivo de la creación de herramientas que se desprende del pensamiento moderno. De este enfoque son ejemplos claros los trabajos - desde ángulos diferentes, claro está- de Richard Sennett (2009), Arturo Escobar (2014) y Jacques Ellul (2003), entre otros.

En este sentido, y tal como ya se señaló, con la teoría de los códigos no es posible decir nada de la esencia como continuum de donde un ser humano selecciona unidades semánticas para darle significado a su experiencia. Debe quedar claro que este es un tema de la fenomenología, que escapa a las posibilidades de la teoría de los códigos. Sin embargo, cuando la esencia de la técnica permite significar y comunicar el gesto técnico, entramos en el ámbito de la cultura, y ahí sí es posible señalar su expresión y contenido porque, desde la teoría de los códigos, la esencia de algo (lo que algo es) corresponde a lo que un ser pensante produce y reconoce que es a partir de una convención socialmente aceptada o generada por él. Por tanto, con base en la teoría de los códigos, un ser humano puede identificar la expresión y el contenido de la estructura del emplazamiento de la técnica moderna como un código y una nebulosa de campos semánticos que caracterizan la cultura alfabética, en oposición a un código y unos campos semánticos que definen la cultura premoderna de la totalidad, es decir, esa forma de pensar que no se orienta por el diseño y la perspectiva analítica y categorial, con la cual se pueden prever los resultados. De esta forma, resulta por lo menos paradójico que la opción por tradicionales formas premodernas de vida sea una consecuencia del dominio del código y los campos semánticos de la racionalidad moderna. Es decir, al parecer solo el dominio del código que configura la cibercultura permite una revisión crítica de sus efectos en el conjunto social, y por tanto, una resistencia activa para entenderla no hace otra cosa que negar la posibilidad de reconocer sus efectos y las posibilidades de integración en la experiencia cotidiana. Porque si alguien no domina el código alfabético, ni los campos semánticos que permiten explicar los fenómenos de complejización de la técnica contemporánea, simplemente debe confiar en lo que señalan quienes sí lo hacen, o peor aún, debe apelar al conocimiento común para entender un fenómeno cuyo origen es una cultura especializada, ¿acaso no fue el riguroso conocimiento filosófico lo que condujo a Heidegger a las conclusiones sobre la esencia de la técnica? Lo mismo ocurre con los demás fenómenos de la cibercultura: para prever los peligros, pero también para identificar lo que puede salvarnos, se requiere dominar el código alfabético.

\section{La tecnología de la información en la organización social}

Por último, los análisis de los cambios de la técnica en la organización social, que se señalaron en la primera parte del texto, se concentran en por lo menos tres perspectivas subyacentes: la histórica, la sociológica y la económica. En la primera se cuentan los trabajos de Lewis Munford (1992), Asa Briggs y Peter Burke (2002), Armand Mattelart (2002), entre otros, que dan cuenta de la evolución de los sistemas técnicos y su relación con la configuración de la sociedad occidental. La perspectiva sociológica ha sido desarrollada por investigadores como Manuel Castells (2000), cuyos aportes constituyen gran parte de la base teórica de los estudios de ciencia y tecnología, 
y los programas de ciencia, tecnología y sociedad. Desde esta perspectiva, se analiza la configuración de la llamada sociedad de la información y los fenómenos sociales y de organización política que se desprenden del acceso masivo a equipos electrónicos de información. Por último, se encuentran los estudios de economía política que se ocupan del análisis de las relaciones de producción que configuran los seres humanos en la sociedad de la información, tales como los elaborados por Zukerfeld (2017) y Bolaño (2013). Desde estos conceptos se analizan fenómenos como la configuración de nuevas formas de ser trabajador, de constituir industrias, de producir y de acceder al capital, con base en el dominio de la información que sirve a la productividad y la eficiencia técnica.

En relación con este último aspecto, la teoría de los códigos contribuye a delimitar los campos semánticos con los cuales se produce y reproduce la tecnología de la información, pero, sobre todo, permite identificar las reglas y el proceso de significación que lleva a la hipocodificación que se encuentra detrás de los avances tecnológicos. Con esta perspectiva, los estudios históricos, sociológicos y económicos, con los cuales se analiza la intención educativa de democratizar el conocimiento y reducir la desigualdad, pueden ir más allá de la descripción de los cambios que produce la tecnología en las formas de vida, para entender la racionalidad, el dominio de los campos semánticos y las reglas con las que se producen y reproducen ciertos objetos y sistemas técnicos.

\section{Conclusión}

Como se ha señalado, con el concepto de cibercultura se designa un cambio cultural generado por el avance de la tecnología en dos aspectos fundamentales: biotecnología y automatización algorítmica de las actividades humanas. Sin embargo, el análisis académico de este fenómeno ha resultado en posiciones opuestas que dificultan su compresión en las ciencias sociales. Desde nuestra perspectiva, parte del problema se debe a cierta comprensión antropológica de la cultura con la cual se fija la atención en el cambio en las formas de vida que genera el sistema técnico moderno y no en la racionalidad que le da origen y permite comprenderla críticamente. La consecuencia de esta tendencia es la descripción permanente de los cambios en dos claves opuestas: una tecnofóbica y otra tecnofílica. La primera, que configura una visión apocalíptica de la tecnología, genera una relación de distancia y extrañamiento con la técnica moderna, con la cual se busca reestablecer una especie de relación premoderna con la tecnicidad humana. En cambio, la segunda advierte todo tipo de transformaciones que a veces rayan en la ciencia ficción: por ejemplo, desde esta perspectiva se habla con desparpajo del vaciamiento de conciencia en computadoras y de las máquinas de soñar y amar que pronto superarán el frágil e imperfecto cuerpo humano.

Como alternativa a esta tensión de pares opuestos, se propone el uso de la teoría de los códigos con el fin de configurar una interpretación propiamente culturalista de la cibercultura. Con ello se muestra la continuidad entre naturaleza y cultura que está detrás de la relación entre el gesto y la palabra, la cual ha hoyado el antropocentrismo que trajo consigo el humanismo, según el cual, el hombre es la medida de todas las cosas, y por esa razón está por encima de los demás seres vivos y los objetos técnicos. Como esta mirada no admite la continuidad evolutiva con otras especies y tampoco puede reconocer el carácter acumulado de la cultura en los objetos técnicos, termina configurando un humanismo fácil que se opone a todo aquello que nos obligue a redefinir nuestra compresión de lo humano. Para ello, el análisis propuesto incluye la revisión de la característica antropológica de la técnica y el lenguaje con el fin de separar en la discusión tres aspectos fundamentales: la evolución de la tecnicidad humana, la facultad de simbolización como facultad creativa y cualidad, y la configuración sociohistórica del acumulado técnico. Con la descripción de la evolución de la tecnicidad humana, que constituye el gesto, se reconoce el papel del modelo perceptivo en la construcción de los significados y con ello se advierte el carácter decisivo de la organicidad humana en la construcción de significados y sentidos compartidos; aspecto hasta ahora imposible de crear por fuera de las coordenadas genéticas de nuestra especie. Por su parte, la facultad de simbolización se reconoce como una facultad creativa con base en reglas que constituyen convenciones culturales, pero también se advierte la existencia de una cualidad innata de producir los significados que va de la mano de cierta configuración sociohistórica de la cultura. Para el análisis de la cibercultura, esta diferencia resulta trascendental porque permite separar los objetos de la sociología e historia de la técnica de los estudios fenomenológicos de la estructura de la conciencia y la experiencia, que se encuentran en la base de la técnica y el lenguaje como formas de conocer y revelar lo que está oculto ahí adelante (tal como diría Heidegger). Además, señala una ruta para conciliar los dos análisis con base en dos preguntas: ¿Qué es lo histórico de la forma de entender la técnica? ¿Cuál es la esencia de la técnica más allá de la historia de la técnica? Porque perder de vista esta diferencia puede llevar a confundir una forma histórica de entender la técnica, la premoderna por ejemplo, con lo que constituye su esencia. 
Por último, el análisis propuesto en este texto permite entender problemas de reproducción social que interesan al campo de la educación, de la mano de dos conceptos derivados de la teoría de los códigos: la hipercodificación y la hipocodificación. Por un lado, la primera señala la búsqueda de apropiación y recreación de la cultura alfabética que da origen a la cibercultura y permite hacer todo tipo de revisiones críticas de los fenómenos subyacentes. Por el otro, la hipocodificación constituye una apropiación parcial del código alfabético que limita la generación de productos y proceso técnicos, y la toma de postura crítica en relación con la técnica moderna. Esta diferencia ayuda a entender, por ejemplo, cuáles son las formas de expresión y contenido que conducen al dominio del código alfabético en la institución escolar, y cuáles llevan a un proceso de enculturación común a cargo de los medios.

\section{Referencias}

Briggs, A. y Burke, P. (2002). De Gutenberg a Internet: una historia social de los medios de comunicación. Taurus.

Bolaño, C. (2013). Industria cultural, información y capitalismo. Gedisa

Castells, M. (2000). La era de la información. La sociedad red (vol. I). Siglo xxI.

Eco, U. (1965). Apocalípticos e integrados. Lumen.

Eco, U. (1995). Tratado de semiótica general. Lumen.

Ellul, J. (2003). La edad de la técnica. Octaedro.

Escobar, A. (2005). Bienvenidos a Cyberia. Notas para una antropología de la cibercultura. Revista de Estudios Sociales, 22, 15-35. http://www.scielo.org.co/pdf/res/ n22/n22a02.pdf

Escobar, A. (2014). Sentipensar con la tierra: nuevas lecturas sobre desarrollo, territorio y diferencia (Introducción y el desarrollo (de nuevo) en cuestión). Universidad Autónoma Latinoamericana. http://biblioteca.clacso. edu.ar/Colombia/escposunaula/20170802050253/ pdf_460.pdf

Habermas, J. (2010). El futuro de la raza humana. ¿Hacia una eugenesia liberal? Paidós.

Haraway, D. (1995). Manifiesto cyborg: ciencia, tecnología y feminismo socialista a finales del siglo xx. Ciencia, cyborgs y mujeres. La reinvención de la naturaleza (pp. 251-311). Cátedra.

Heidegger, M. (2001). La pregunta por la técnica. En E. Barjau (trad.), Conferencias y artículos (2. ed ed.) (pp. 9 -37). Ediciones del Serbal. (Original publicado en 1954).
Hjelmslev, L. (1984). Prolegómenos a una teoría del lenguaje. Gredos.

Kurzweil, R. y Grossman, T. (2004). Fantastic voyage. Live long enough to live forever. Rodale.

Lacadena, J. (2017) Edición genómica: ciencia y ética. Revista Iberoamericana de Bioética, (3), 1-16.

Leroi-Gourhan, A. (1971). El gesto y la palabra. Técnica y lenguaje. Universidad Central de Venezuela.

Levy, P. (2007). Cibercultura: la cultura de la sociedad digital. Anthropos.

Mattelart, A. (2002). Historia de la sociedad de la información. Paidós.

Mockus, A., Hernández, C. A., Granes, J., Charum, J. y Castro, M. C. (1994). Las fronteras de la escuela. Sociedad Colombiana de Pedagogía.

Munford, L. (1992). Técnica y civilización. Alianza.

Narváez, A. (2012). Cultura alfabética, educación y desarrollo. Pedagogía y Saberes, (36), 81-92. https://doi.org/1 $0.17227 / 01212494.36$ pys81.92

Narváez, A. (2013) Educación y comunicación: del capitalismo informacional al capitalismo cultural. Universidad Pedagógica Nacional; DIE.

Rodríguez, P. (2007). [Reseña de El modo de existencia de los objetos técnicos por Gilbert Simondon]. Redes, 13(26), 277289. http://www.redalyc.org/pdf/907/90702617.pdf

Saussure, F. (1982). Curso de lingüística general. Nuevo Mar. Sennett, R. (2009). El artesano. Anagrama.

Simondon, G. (2008). El modo de existencia de los objetos técnicos. Prometeo.

Sloterdijk, P. (2000). Normas para el parque humano. Siruela

Sloterdijk, P. (2012). Has de cambiar tu vida. Sobre antropotécnica. Pre-Textos.

Stone, A. R. (1991). Virtual systems: The architecture of elsewhere. Santa Cruz: Group for the Study of Virtual Systems, Center for Cultural Studies [manuscrito inédito]. University of California.

Virno, P. (2005). Cuando el verbo se hace carne: lenguaje y naturaleza humana (E. Sadier, trad.). Traficantes de Sueños.

Zukerfeld, M. (2017). Knowledge in the age of digital capitalism: an introduction to cognitive materialism. University of Westminster Press. http://www.jstor.org/stable/j. ctv6zd9v0 